\title{
Interventions for sleep problems during pregnancy: a systematic review
}

Valeria Bacaro ${ }^{* 1}$; Fee Benz ${ }^{2}$; Andrea Pappaccogli ${ }^{1}$; Paola De Bartolo ${ }^{1}$; Anna F. Johann ${ }^{2,3}$; Laura Palagini $^{4}$; Caterina Lombardo ${ }^{5}$; Bernd Feige ${ }^{2}$; Dieter Riemann ${ }^{2}$; Chiara Baglioni ${ }^{1,2}$

${ }^{1}$ Department of Human Sciences, University of Rome “G. Marconi”- Telematic, Rome, IT.

${ }^{2}$ Department of Psychiatry and Psychotherapy, Medical Center - University of Freiburg, Faculty of Medicine, University of Freiburg.

${ }^{3}$ Medical Psychology and Medical Sociology, Faculty of Medicine, University of Freiburg, Germany.

${ }^{4}$ Department of Clinical and Experimental Medicine, Psychiatric Clinic, University of Pisa, Italy.

${ }^{5}$ Department of Psychology, Sapienza University of Rome, Rome, Italy.

*Corresponding author: Valeria Bacaro; v.bacaro@ unimarconi.it; Via Plinio, 44 - 00193 Roma - Tel. +3906377251 - Fax +390637725212.

Running title: Treating sleep problems during pregnancy

\section{Conflicts of interest}

All authors report no competing interests. 


\section{Summary}

Sleep problems during pregnancy are prevalent and could be linked to negative outcomes during pregnancy or post-partum. However, these complaints are often underdiagnosed and undertreated. This review aimed to systematically assess the effectiveness of different interventions to ameliorate poor sleep quality and insomnia during pregnancy.

Pubmed, PsycINFO and Medline databases were systematically searched without publication period restriction until $3^{\text {rd }}$ May 2019. Eligible studies had to: include pregnant women of any age and gestational age; use clinical intervention designs targeted at improving sleep outcome; report pre- and post- treatment data for one or more sleep-related outcomes; be published in English, Italian, German, Spanish, or French.

Sixteen studies were selected including 1252 expecting mothers. Studies evaluated the efficacy of various interventions: cognitive behavioral interventions for insomnia (4); pharmacotherapy (1); acupuncture (1); mindfulness and yoga (3); relaxation (5) and herbal medication (2). Only six were randomized controlled trials, and only four evaluated longitudinal outcomes. Preliminary support was found for all interventions, but our knowledge is still too limited by lack of evidence.

There is an utmost urgency to perform high-quality randomized controlled trials for insomnia interventions during pregnancy and to implement effective programs in standard gynecological care.

Keywords: Intervention; Treatment; Insomnia; Sleep quality; Pregnancy; Maternal mental health; Systematic review 


\section{Abbreviations:}

CBT, cognitive behavioral therapy;

CBT-I, cognitive behavioral therapy for insomnia;

MMT, mindfulness mom training;

PICOS, population, intervention, comparison, outcomes and study design;

PRISMA, preferred reporting items for systematic reviews and meta-analyses;

PSQI, pittsburgh sleep quality index;

RCT, randomized controlled trial;

$\mathrm{SD}$, standard deviations;

SE, standard errors;

SIP-AP, sleep improvement protocol from antepartum patients;

TAU, treatment as usual. 


\section{Introduction}

Sleep is crucial for life, occupying up to a third of the human life span. Poor sleep, either in duration, continuity, or quality, is linked with increased risk for negative health outcomes such as cardiovascular disease, diabetes, depression and anxiety [1-4]. Sleep is an important regulatory psychophysiological process influencing emotion regulation and impulsive behavior [5, 6], which are key mediators of stress adjustment [7]. Insomnia disorder is among the most common complaints in medical practice [8] and it is associated with high direct and indirect costs [9].

Specifically, during pregnancy, women experience sleep disturbances which increase the risk of developing insomnia [10]. The National Sleep Foundation's Women and Sleep Survey in 2007 found that up to $78 \%$ of women complained about disturbed sleep during the third trimester of pregnancy [11]. However, pregnant women experience alterations in sleep duration [12, 13], quality [14, 15] and pattern [15-17] across all gestational weeks, and not only during late pregnancy [e.g. 18].

Poor sleep quality during pregnancy has been found to be a prospective risk factor for depression during the prenatal and postpartum period [19-21]. Supporting these data, recent studies showed that sleep disturbances are associated with adverse pregnancy outcomes including intrauterine growth restriction (poor growth of fetus while in the mother's womb during pregnancy), preterm birth, higher risk of cesarean birth and longer labor [22-24]. Psychosocial factors as low socio-economic status, problematic work situation, low educational level, lacking access to prenatal care, drug abuse and conflicts with the partner all contribute to stress during pregnancy [25]. Evidence has shown that a poor sleep quality may be also related to high-levels of experienced stress, and that both are associated with immunological and endocrinological problems, as well as higher morbidity risk [26]. Sleep is likely both an outcome and a predictor of increased levels of stress during pregnancy, which may be linked to a cascade of negative consequences for the birth, the mother and the child. 
Nevertheless, there is a tendency to routinely exclude pregnant women from clinical trials evaluating interventions for sleep problems and insomnia [27] and a tendency for mothers to commonly report sleep problems late in pregnancy, even though the problems often started already during the first trimester [15], making women who could benefit from the treatment ineligible [28]. This could lead to underdiagnoses and under-treatment of insomnia and sleep complaints during pregnancy, consistently with what happens for maternal mental health in general [e.g. 29, 30]. Furthermore, it is likely related to a hesitancy to prescribe hypnotic and psychotropic medication to expectant or breastfeeding mothers because of feared side-effects for the mother and child [29]. While data are available indicating that also the expectant mothers themselves would prefer psychotherapy to pharmacotherapy or other types of intervention for mental problems as well [31], limited evidence is available for the efficacy of psychotherapy during pregnancy due to a low number of studies and small sample sizes [e.g. 32, 33]. Pregnant and breastfeeding mothers are indeed routinely excluded from biomedical research. As F. Baylis [34] pointed out: "this is unethical and unscientific and regulators must mandate change". Indeed, our knowledge on health-related psychobiological processes in this life period is limited, and so is our related ability to effectively treat and prevent mental disorders, including sleep problems. This limitation needs to be overcome as guidelines demand that efficacious psychological treatments should be available to pregnant women [33].

European and American guidelines $[9,35]$ underline that insomnia is effectively treated by cognitive behavioral therapy for insomnia (CBT-I), which is the first-line treatment for insomnia and related problems. Cumulative evidence shows that CBT-I has a beneficial effect on comorbid symptoms [36, 37], thus having the potential to prevent negative health outcomes [38].

Targeting sleep during pregnancy offers huge potential gains both from a research and a clinical perspective, to alleviate women's night and daytime sleep-related symptoms as well as for preventive 
effects. As stated above, sleep is a crucial risk factor for depression and mental disorders during pregnancy. CBT-I is effective for comorbid symptoms [1-4], easily implemented in standard care and, thus, could, represent an efficacious preventive intervention [9].

In addition, a study was conducted to investigate the preferences of 187 pregnant women regarding the treatment of insomnia. Results showed that most participants (51\%) preferred CBT-I as a treatment for insomnia over pharmacotherapy (12\%) or acupuncture (37\%). Participants also perceived CBT-I to be the most credible treatment and expected it to be the most effective for them personally [39].

Summarizing the state of the art on evidence-based literature evaluating the efficacy of health and clinical interventions for sleep problems during pregnancy, sleep complaints are prevalent and have important health consequences. Nevertheless, as stated above, these problems are often underrecognized and undertreated in clinical settings. It is so far not clear which treatments are proposed to be effective and which have received empirical support and should be implemented across pregnancy primary care. Systematic reviews and meta-analyses are useful to identify the state of the art on a specific topic and to underline whether there is a lack of evidence requiring more attention from the scientific community. Thus, there is urgency to systematically review the evidence-based literature on this specific topic and to evaluate its consistency and quality to direct future clinical and research advances in this area of healthcare. The present work aimed to systematically identify and critically assess the evidence for the use of different interventions (pharmacological, psychological, behavioral, and alternative interventions) in order to ameliorate sleep quality, sleep complaints and insomnia during pregnancy.

\section{Methods}

The study was conducted in accordance with the Preferred Reporting Items for Systematic Reviews and 
Meta-Analyses (PRISMA) recommendations for reporting systematic reviews and meta-analyses [40] (see Document S1 in Supplemental Material) and preregistered in the PROSPERO database, registration ID: CRD42019117295.

\section{Study selection}

Study eligibility was assessed using the Population, Intervention, Comparison, Outcomes and Study design (PICOS) approach [41]. PICOS is a structured approach for framing questions using five components: the patient population or the disease being addressed (P), the interventions or exposure (I), the comparison group $(\mathrm{C})$, the outcome or endpoint $(\mathrm{O})$, and the study design chosen $(\mathrm{S})$. In order to be included, studies had to fulfill each of the following inclusion criteria: 1) Population: pregnant women of any age and any gestational age; 2) Intervention: clinical intervention targeting sleep quality, sleep complaints, insomnia or insomnia-related symptoms; 3) Comparison group and Outcomes: pre- and post-treatment data for both intervention and controls (when available) for one or more sleep-related outcomes, including the primary outcomes of insomnia symptoms, sleep quality and the secondary outcomes of sleep parameters (total sleep time, sleep onset latency, wake after sleep onset, sleep efficiency index), fatigue, somnolence and mood; 4) Study design: clinical studies reporting results as either pre-post means and standard deviations or standard errors (SD/SE) in all groups, change-scores in all groups, or effect sizes (e.g., Cohen's d, Eta ${ }^{2}$ ); 5) Language: English, Italian, German, Spanish, French. No publication period restriction was made.

\section{Search procedure}

Several strategies were used to identify the final study sample.

No time restriction was applied in order to collect data from all studies published so far on the topic.

First, databases "Pubmed", "PsycINFO" and "Medline" were systematically searched without starting 
time restriction until 3rd May 2019 according to the following expression: (((pregnan*[Title/Abstract] OR "expect* mother*"[Title/Abstract] OR "mother*"[Title/Abstract])) AND ((insomnia*[Title/Abstract] OR sleep*[Title/Abstract])) AND ((treat* [Title/Abstract] OR therap*[Title/Abstract] OR intervention [Title/Abstract]))). First and third authors conducted the literature search, screened titles and abstracts of potentially eligible studies, examined the full texts and extracted descriptive data collaborating whenever the inclusion or exclusion of one study was doubtful. The final selection of articles was discussed by the first and last authors.

Second, we expanded our search through identifying further studies from the references of the screened full-texts.

Third, in order to collect data from non-published studies, the first author screened published conference proceedings from sleep-related journals from 2014 to 2019. Moreover, we contacted authors in the field (mailing list of the European Insomnia Network) to obtain further data and, if needed, to obtain additional information, especially on potential overlaps between samples of different studies. The searches and the screening was run on Citavi 6 software (https://www.citavi.com).

\section{Data extraction:}

The first and the third authors independently extracted data to confirm accuracy. Any doubt was discussed together with the help of the other authors. For each selected study, socio-demographic, clinical and methodological variables were extracted. When provided, data on maternal age (in years), gestational age (in weeks), trimester, parity were also extracted. Specifically, we extracted the following data: information about population characteristic (clinical/non clinical); sample size; mean age; mean age per group; age range; mean gestational age; mean gestational age per group; parity; study design; country; intervention; control; duration of the intervention; number of sessions; duration 
of each session (or medication dose); intervention's conductors; sleep outcome; other outcome; follow ups.

Risk of bias assessment:

Since non- randomized controlled trials (RCT) used very different study designs often associated with high risk of bias, we conducted a systematic risk of bias assessment only for the RCT studies. Particularly, we used the Cochrane Collaboration's tool for assessing risk of bias [42]. This tool assesses the following potential areas of bias:

1) Selection bias: evaluation of recruitment and randomization methods;

2) Performance bias: evaluation of the blinding of participants and personnel.

3) Detection bias: evaluation of awareness of outcome assessors about the intervention or exposure status of participants;

4) Attrition bias: evaluation of withdrawals and drop-outs;

5) Other sources of bias: a) Confounders: evaluation of important differences between groups prior to the intervention on confounding variables (e.g., race, sex, marital status, age, health status); b) Data collection methods: evaluation of validity and reliability of instruments.

Bias is assessed as a judgment (high, low or unclear) for individual elements of these five domains. The first and the second authors independently rated each study, and disagreements were resolved through decision by consensus. For judging each item of each domain first and second authors used the grid created by Cochran Collaboration [42] in which specific criteria are explained. The final score identified whether a study was either at low, unclear or high risk of bias, following the Cochrane Collaboration guidelines. 


\section{Results}

Study selection

Figure 1 illustrates the detailed flow chart of the selection process. Database searching yielded 3225 abstracts (PubMed: $\mathrm{n}=1748$; PsycINFO: $\mathrm{n}$ 439; Medline: $\mathrm{n}=1038$ ). Of these, 1420 were duplicates; after removing duplicates a total of 1805 abstracts remained. Titles and abstracts were examined for relevance and 1785 were excluded. Reference lists of the retrieved original articles were screened but no more records were found. Twenty records were scrutinized and 4 studies were excluded for the following reasons: study design (no intervention studies; $n=2$ ); outcome assessed (no sleep related outcome; $\mathrm{n}=2$ ). A total of 16 studies met the inclusion criteria and were therefore reviewed.

Please insert here Fig. 1: Search flow diagram

\section{Study characteristics}

A summary of the included studies is reported in Table 1. Additional qualitative information is reported in supplementary material in Document S2. Of the included studies, six were RCT [43-48], testing the efficacy of the following different interventions: use of lavender cream, pharmacotherapy, CBT-I, relaxation exercise, use of lactuca seeds and sleep hygiene. Ten were non-randomized trials testing the efficacy of acupuncture [49]; mindful yoga [50]; music listening relaxation [51] and general relaxation [52, 53]; cognitive behavioral therapy interventions [54, 55]; mindfulness [56]; massage therapy [57] and tai-chi [58]. The sample size of all included studies ranged from a minimum of 13 to a maximum of 215 participants. The studies included data from 1252 women, aged on average 28.9 years. Reported mean gestational age varied across studies from 17 weeks to 30 weeks with five studies not reporting 
this information $[43,46,51,53,58]$. Only three studies $[47,50,53]$ had a sample composed of nulliparous women exclusively. Studies were conducted in 12 different countries, the $50 \%$ in the United States and none in Europe. Of the included studies, six included healthy women with no complaints $[46,50,52,53,55,57]$, seven included healthy women with self-reported sleep problems [43, 44, 47-49, 51, 54]; one study had participants with insomnia diagnosis [45], one reported data for obese women [56] and one included women with clinical depression [58]. Furthermore, the majority of the included studies $(n=10)$ used only self-reported measures as outcomes; two studies [44, 53] used only actigraphy and four studies $[45,50,54,55]$ used both subjective/objective sleep parameters (diaries or actigraphy) and self-reported measures. Only four of the included studies carried out follow ups $[43,44,48,53]$.

Please insert here: Table 1: "Study characteristics" 


\section{Risk of bias assessment for randomized controlled trials}

Detailed risk of bias assessment evaluations are presented in supplementary material Document S3 including judgments (low risk, unclear or high risk) and reasons based on Cochrane's criteria.

Risk of bias assessment scores are presented in Figure 2. Only one study [45] had a judgment of "high risk" in the attrition bias. Indeed, in this study, despite attrition and exclusions were reported, the attrition rates differed between the two groups (intervention/control). One study [46] had four "unclear" judgments as there was a lack of detailed information regarding allocation concealment, blinding of participants, and no study protocol was reported.

Please insert here Fig. 2: "Quality of randomized controlled trials"

\section{Critical evaluation of level of evidence of non-randomized controlled trials}

Ten studies were non-RCT $(n=10)$. Of these, two studies had no control group $[52,54]$, and one further study used baseline data of women who began the intervention in the third trimester of pregnancy as the control for post-treatment [50]. Three studies did not report mean gestational age $[51,53,58]$ of the participants, and only one study [53] included follow-up analyses. Finally, the majority of the non-RCT studies had exiguous samples, indeed seven studies had a sample with less than 40 participants [49, 50, $52-55,57]$.

Efficacy of cognitive behavioral interventions

As stated before, CBT-I is a non-pharmacological insomnia-focused psychotherapy, recommended as 
the first-line treatment for insomnia by American and European guidelines [9, 35]. CBT-I has also been identified by pregnant women as their treatment of choice, compared with pharmacotherapy and acupuncture [39]. However, little is known about its effectiveness for prenatal insomnia. In our systematic review four studies tested the efficacy of CBT-I or cognitive behavioral therapy (CBT) strategies on sleep and insomnia-related outcomes.

Manber et al. [45] evaluated through a RCT the efficacy of CBT-I compared to psychoeducation control therapy in an ethnically diverse sample of pregnant women who were not depressed and did not receive any other treatments for insomnia disorder. The primary outcome was the insomnia severity score [59] and secondary outcomes were rates of remission of insomnia disorder, objective and selfreport measures of time awake at night (i.e. total wake time), and depression symptoms. Results showed that women who received CBT-I had greater improvement in insomnia symptom severity; shorter time to remission time of insomnia; reduced self-reported total wake time and reduced depression symptoms compared to control therapy.

Tomfohr-Madsen et al. [54] assessed the efficacy of 5-weeks CBT-I intervention in a pilot study on 13 healthy pregnant women (mean gestational age 19.31 weeks) with self-reported sleep problems. Outcomes of this study were insomnia symptoms and sleep parameter measured with both sleep diaries and actigraphy. Results showed that on average insomnia symptoms decreased such that participants no longer reported clinically significant insomnia after treatment. Sleep diary variables including total sleep time and sleep efficiency significantly increased after the intervention. Actigraphy results showed a significant increase of sleep efficiency and decrease of sleep onset latency after the intervention.

Lee et al. [55] tested the efficacy of a sleep health behavioral education intervention compared to usual prenatal care on 25 healthy pregnant women (on average at $29^{\text {th }}$ gestational week). Results showed that the intervention significantly reduced self-reported insomnia symptoms compared to the control group. 
No other significant results in other outcomes were found.

Finally, Rezaei et al. [48] conducted a RCT in 112 healthy pregnant women with self-reported sleep problems in order to test the efficacy of sleep health behavioral education compared to usual prenatal care. Results showed that sleep quality was increased after intervention and at follow up compared to before intervention.

\section{Efficacy of pharmacotherapy intervention}

Pharmacotherapy for insomnia is frequently prescribed off-label, for example benzodiazepine receptor agonists, antidepressants, and gamma-aminobutyric acid reuptake inhibitors [60]. Regarding the possible side effects of pharmacotherapy for treatment of insomnia in prenatal period, some authors suggested that benzodiazepine and benzodiazepine receptor agonists are associated with increased risk of preterm labor, low birth weight and small-for-gestational-age infants [61]. Particularly, zolpidem has been associated with preterm birth, cesarean birth, and low-birth-weight infants [62].

Khazaie et al. [44] performed a RCT in order to investigate the efficacy of pharmacotherapy (trazodone and diphenhydramine) compared to placebo on objectively measured sleep parameters. They found no significant differences after 2 weeks of treatment between the two groups. However, after 6 weeks of treatment the experimental group showed longer sleep duration and higher sleep efficiency compared to placebo group. Participants in both trazodone and diphenhydramine groups reported daytime sleepiness as most frequent side-effect.

\section{Efficacy of mindfulness and yoga interventions}

Mindfulness derives from the tradition of meditation where individuals exercise an intentional awareness to present thoughts and sensations with acceptance and no judgment $[63,64]$. Mindfulness strategies play a role in reducing stress and regulating emotional reactivity. Both mechanisms are 
particularly useful in attenuating the cognitive and somatic arousal associated with insomnia [65]. Increasing evidence suggests that mindfulness-based interventions may improve well-being during pregnancy. Furthermore, yoga intervention studies reported that yoga significantly improves sleep quality, for example, results from one study suggest that yoga may be efficacious to sleep [66]. They implemented a prenatal yoga intervention and demonstrated significantly lower incidences of adverse perinatal outcomes in the treatment group compared to controls.

In our systematic review, one study from Beddoe et al. [50] assessed the efficacy of a 7 week mindfulness based yoga intervention on subjective and objective sleep quality and sleep pattern in pregnant women. They found that women who began the yoga program in their second trimester reported less wake time and less perceived sleep disturbance versus women who began the intervention in their third trimester. The study from Felder et al. [56] assessed the efficacy of a Mindfulness Mom Training (MMT) compared to treatment as usual (TAU) on sleep quality in 215 obese/overweight pregnant women. MMT included elements to support healthier eating and encourage physical activity, and focused on increasing attention to awareness of physical sensations, thoughts, and emotions, and accepting negative experiences versus ruminating about them. They found that MMT participants did not experience significantly greater improvement in sleep quality compared to TAU participants. However, poor global sleep quality predicted increased depression symptoms for both groups.

The last study included in our systematic review that assessed the efficacy of yoga and tai-chi intervention compared to waiting list control on subjective sleep quality in 92 women with clinical depression was by Field et al. [58]. They found that the tai chi/yoga group showed greater decreases in self-reported sleep problems as well as in depression and anxiety scores compared to the control group.

\section{Efficacy of relaxation interventions:}

Several studies on relaxation exercises during pregnancy indicate that these exercises have various 
effects on biological and psychological stress systems, prolong pregnancy in pregnant women with preterm delivery risk, and increase birth weight [67-69].

In our systematic review, five studies assess the efficacy of relaxation intervention on sleep quality in pregnant women.

The first study from Liu et al., [51] evaluated the effects of a two-week relaxation intervention, consisting in listening to music, compared to usual prenatal care, in healthy Taiwanese pregnant women with self-reported sleep quality problems. Pregnant women in the experimental group were instructed to listen to at least one disc (30 minutes) or a minimum of 30 minutes of their preferred music per day at bedtime for two weeks. Women in the experimental group reported significantly higher sleep quality after this time.

Moreover, Schaffer et al. [52] tested the efficacy of an 8-week guided imagery relaxation intervention on self-reported sleep quality in 20 healthy pregnant women. The intervention used a professionally produced CD (compact disc). Each track provided images to promote increased relaxation, capacity to work with difficult feelings, and self-empathy. Study participants were asked to listen to a track at least once a day but could listen more than once. They were advised to use the CD at any time of the day they preferred. They found that as the average amount of time spent listening per week increased, Pittsburgh Sleep Quality Index (PSQI) [70] scores decreased.

The third study included [57] focused on massage and relaxation interventions. Authors found that massage and relaxation interventions twice a week for five weeks had a positive impact on pregnant women by decreasing stress hormones and potential stressors, and improving mood and sleep.

Furthermore, Ozkan et al. [46] assessed the efficacy of a relaxation intervention with a RCT. Particularly, pregnant women were provided with a $\mathrm{CD}$ with relaxation exercises to perform at bed 
time for 4 weeks. Their sleep quality was assessed by PSQI at baseline and at post-intervention. The study found significant differences between the relaxation exercises group and the control group in terms of subjective sleep quality, sleep latency, sleep duration, habitual sleep efficiency, sleep disturbances, and daytime dysfunction in favor of the relaxation exercises group.

Finally, Lee et al. [53] evaluated the effect of Sleep Enhancement Training System for Pregnancy treatment in a sample of 25 healthy pregnant women aged on average 32.7 years. Sleep Enhancement Training System for Pregnancy was a 4-weeks intervention during which women were instructed to listen to material provided on an MP3 player before going to sleep each night. The sound-enhanced relaxation training included guided imagery, muscle relaxation, and breathing techniques to reduce arousal and promote sleep. Participants in the control group were provided with a pamphlet containing recommendations for healthy eating and information about how diet can influence sleep. Two sleeprelated outcomes were evaluated using actigraphy: nocturnal sleep duration (total sleep time in minutes) and nocturnal sleep disruption (wake after sleep onset in minutes). Results showed that participants in the experimental group had significantly longer sleep duration and less sleep disruption compared to participants in the control group, and also that this effect was stronger at the follow-up assessment (one month after delivery).

\section{Efficacy of alternative interventions}

Several alternative treatments for insomnia have been suggested, including for example acupuncture, acupressure, aromatherapy, foot reflexology, homeopathy, meditative movement therapies, moxibustion [35]. Despite that, studies underlying this evidence are methodologically poor and thus the generalizability of results is difficult to evaluate.

In our systematic review, Guerreiro da Silva et al. [49] evaluated the effect of acupuncture. This 
intervention study evaluated the effect of acupuncture and sleep hygiene compared to only sleep hygiene on self-reported sleep problems in 30 pregnant women. They found that both groups reported less insomnia symptoms after the intervention, but that the reduction was greater in the group involved in acupuncture and sleep hygiene intervention. Moreover, they did not find important adverse effects of acupuncture effects during the study and in the post-partum period.

Furthermore, two studies were included that evaluated the effects of herbal medication treatment.

Effati-Daryani et al. [43] evaluated the effect of lavender cream with or without footbath, compared to placebo, on sleep quality and fatigue in pregnancy and postpartum with an RCT. The sample of this study was composed of 141 pregnant women aged 18 to 40 years, whose parity was one to three and who were at 25 to 28 weeks of gestation and with self-reported sleep problems. They found that the Lavender and footbath group showed an increase in sleep quality both during pregnancy and at follow up (6 weeks after the delivery), and decreased fatigue scores only at follow up assessment.

Finally, Pour et al. [47] performed an RCT on the effect of Lactuca sativa L. seeds on 100 outpatient pregnant women who complained of insomnia. Women aged 20 to 45 years with singleton pregnancies and at a gestational age of 12 to 36 weeks were included. Participants in the experimental group were asked to take one capsule every night for two weeks (lettuce seed group), while the control group received placebo capsules. Results showed that intervention was efficacious in improving sleep quality in the experimental group. 


\section{Synthesis and conclusion}

This is the first systematic review assessing current evidence of interventions for sleep problems and complaints during pregnancy. We included sixteen studies involving different types of interventions and study designs. For this reason, results are not statistically comparable in terms of outcome, type of design and type of intervention. Despite that, in table 2 we summarized the main results for each study, highlighting intervention type, characteristic and assessed outcome.

Please insert here Table 2: Efficacy of different intervention on assessed outcome

CBT-I interventions appear to be efficacious in pregnant women. Tomfohr-Madsen et al. [54] provided promising results showing that CBT-I is well-received and promote an amelioration of sleep in pregnant women. However, this non-RCT study was based on data of only 13 pregnant women. The study from Manber et al. [45] assessed the efficacy of CBT-I using a larger sample size and a RCT design, and it seems to confirm the results from Tomfohr-Madsen et al. [54]. Lee et al. [55] implemented a sleep health behavioral intervention of only seven days and did not find significant improvement in sleep quality and sleep parameters assessed through questionnaires and diaries, but only in self-reported sleep disturbance, suggesting that longer interventions are desirable. In summary, CBT-I and CBT strategies appear to be effective in improving sleep outcomes in pregnant women, confirming what is already known in the general population $[9,35]$. Despite that, our systematic review highlighted a substantial lack of evidence.

Based on the study conducted by Khazaie et al. [44], pharmacotherapy seems to be associated with long-term improvements, but no post-treatment effect. Despite that, the authors reported that the majority of women involved in the study complained about daytime sleepiness as principal side effect. 
It seems reasonable that, similarly to the general population, CBT-I is to be preferred for symptoms of insomnia in pregnant women, also because pharmacotherapy daytime side-effects could be associated with negative pregnancy outcomes or increased maternal stress in this population.

Regarding mindfulness and yoga interventions, the only study that did not find significant improvement after the intervention is the one by Felder et al. [63]. This could be due to the fact that the sample of this study was composed of obese/overweight pregnant women, and it is known in literature that there is an association between obesity and increased sleep disturbance [71-73].

Relaxation interventions seem to be efficacious in improving sleep and insomnia-related outcomes. Despite that, only one study [53] assessed the efficacy of this type of intervention in our systematic review and performed one follow-up assessment at 1 month after the delivery. Based on this study, the effect of this intervention was efficacious both at post-treatment and at follow up assessment.

Studies on alternative medicine report positive effects on sleep outcomes. However, they used selfreported measures, including only questionnaires, and they did not use more ecological measures as sleep diaries or objective or physiological measures. For this reason, in order to assess the efficacy of this type of intervention, more studies using long-term, ecological self-report and physiological measures (like for instance sleep diaries, actigraphydiaries, actigraphy and/or polysomnography pelisomenography and other physiological measures) are needed.

This first systematic review on this topic outlines a severe lack of evidence for clinical preventive and curative support for sleep problems in pregnant women. Despite the large number of women complaining of sleep problems during pregnancy, there is a lack of evidence-based interventions, thus limiting clinical judgment on efficacious treatments. Systematic reviews can demonstrate where knowledge is lacking and, consequently, guide future research to overcome the neglecting of the topic in research and clinical context [74]. 
More effort should be dedicated to clinical research assessing the effectiveness of diverse interventions for sleep problems in this important period of life for both women and for their children. There is a need to improve psychological health care during pregnancy to support a positive course of pregnancy, birth and post-partum. Future clinical studies should be rigorously RCTs, and should conduct followups after the interventions in late pregnancy, and post-partum. Thus, long-term efficacy of the interventions should be evaluated. Studies-Researchers should recruit large samples of women in order to improve statistical power and and to clearly distinguish the nature of sleep problems in pregnancy, particularly between sleep problems and insomnia. Furthermore, since it is well known that physical activity and exercise have a lot of positive health outcome (including ameliorating sleep quality), future clinical studies and RCTs should assess the efficacy of these type of intervention for sleep problems in this population. An important objective would be to repeat this work in the next years and have the possibility to conduct meta-analytic computations, such as a network meta-analysis. This is a statistical method that allows to evaluate the effectiveness of multiple treatments simultaneously combing direct and indirect evidences of treatment differences and to promote guidelines for best-supported evidencebased interventions for insomnia during pregnancy. Indeed, a limitation of this systematic review is that the magnitude of the effects of specific types of interventions was not considered with a meta-analysis. Consistently, studies included in this systematic review assessed the efficacy of very different interventions that were dissimilar from each other in some crucial variables (outcome assessed, type of design and type of intervention). For this reason, and following Cochrane Collaboration [41] and Prisma Guidelines [42] a comprehensive measure of all the effects with meta-analytic calculation would not be informative. Finally, another limitation is due to the low number of studies also using different interventions. Therefore, it is still early to provide clinical guidelines. This limits the possibility of commenting and critically evaluating the literature currently available.

Following the current guidelines, we recommend to test the efficacy of cognitive-behavioural treatment 
for insomnia in large RCT and test its efficacy for sleep and comorbid outcomes in a long-term perspective.

\section{Practice points:}

1. Sleep disorders are among the most widespread major problems experienced during pregnancy. The National Sleep Foundation's Women and Sleep Survey in 2007 found that up to $78 \%$ of pregnant women report disturbed sleep.

2. Despite the high prevalence and their association with many negative outcomes, insomnia and sleep complaints during pregnancy are underdiagnosed and undertreated.

3. There is a lack of guidelines regarding evidence-based interventions for insomnia which work and should be offered to pregnant women.

\section{Research agenda}

1. There is a need to improve psychological and sleep health care during pregnancy to support a positive course of pregnancy, birth and post-partum. Future clinical studies should be rigorously randomized controlled trials, follow-up women after interventions in late pregnancy and post-partum. Thus, long-term efficacy of the interventions should be evaluated. Studies should recruit a large number of women in order to improve statistical power.

2. Following the current guidelines for insomnia, we recommend to test the efficacy of cognitivebehavioral treatment for insomnia in large randomized controlled trials and test its efficacy for sleep and comorbid outcomes in a long-term perspective. 


\section{Acknowledgements}

This work was supported by the Department of Human Science of the University G. Marconi Telematic, Rome (Italy) and by the Department of Psychiatry and Psychotherapy, Faculty of Medicine, University of Freiburg (Germany). We would like to thank Dr. Field for sending further information on their studies for the purpose of our systematic review. 


\section{References}

1. Cappuccio FP, D’Elia L, Strazzullo P, Miller MA. Quantity and quality of sleep and incidence of type 2 diabetes: a systematic review and meta-analysis. Diabetes Care 2010; 33: 414-420.

2. Cappuccio FP, Cooper D, D’Elia L, Strazzullo P, Miller MA. Sleep duration predicts cardiovascular outcomes: a systematic review and meta-analysis of prospective studies. Eur Heart J 2011; 32: 1484-92.

3. *Baglioni C, Battagliese G, Feige B, Spiegelhalder K, Nissen C, Voderholzer U et al. Insomnia as a predictor of depression: a meta-analytic evaluation of longitudinal epidemiological studies. J Affect Disord 2011; 135: 10-19.

4. Hertenstein E, Feige B, Gmeiner T, Kienzler C, Spiegelhalder K, Johann A et al. Insomnia as a predictor of mental disorders: A systematic review and meta-analysis. Sleep Med Rev 2018; 43: 96-105.

5. Gruber R, Cassoff J. The interplay between sleep and emotion regulation: conceptual framework empirical evidence and future directions. Curr Psychiatry Rep 2014; 16: 500.

6. Palmer CA, Alfano CA. Sleep and emotion regulation: an organizing, integrative review. Sleep Med Rev 2017; 31: 6-16.

7. Galderisi S, Heinz A, Kastrup M, Beezhold J, Sartorius N. Toward a new definition of mental health. World Psychiatry 2015; 14: 231-233.

8. Morin CM, Drake CL, Harvey AG, Krystal AD, Manber R, Riemann D, et al. Insomnia disorder. Nat Rev Dis Primers 2015; 1: 15026.

9. *Riemann D, Baglioni C, Bassetti C, Bjorvatn B, Dolenc Groselj L, Ellis JG et al. European guideline for the diagnosis and treatment of insomnia. J Sleep Res 2017; 26: 675-700. 
10. *Palagini L, Gemignani A, Banti S, Manconi M, Mauri M, Riemann D. Chronic sleep loss during pregnancy as a determinant of stress: impact on pregnancy outcome. Sleep Med 2014; 15: 853-859.

11. National Sleep Foundation. Summary of Findings of the 2007 Sleep in America Poll. Available at: http://sleepfoundation.org/media-center/press-release/sleep-america-poll-summary-findings.

12. Elek SM, Hudson DB, Fleck MO. Expectant parents' experience with fatigue and sleep during pregnancy. Birth 1997; 24:49-54.

13. Hutchison BL, Stone PR, McCowan LM, Stewart AW, Thompson JM, Mitchell EA. A postal survey of maternal sleep in late pregnancy. BMC Pregn Childbirth 2012; 12:144.

14. *Mindell JA, Jacobson BJ. Sleep disturbances during pregnancy. J Obstet Gynecol Neonatal Nurs 2000; 29:590-7.

15. Hertz G, Fast A, Feinsilver SH, Albertario, CL. Schulman H, Fein AM Sleep in normal late pregnancy. Sleep 1992; 15: 246-251.

16. Waters MA, Lee KA. Differences between primigravidae and multigravidae mothers in sleep disturbances, fatigue, and functional status. J Nurse Midwifery 1996; 41:364-7.

17. Greenwood KM, Hazendonk KM. Self-reported sleep during the third trimester of pregnancy. Behav Sleep Med 2004; 2:191-204.

18. *Mindell JA, Cook RA, Nikolovski J. Sleep patterns and sleep disturbances across pregnancy. Sleep Med, 2015; 16: 483-488.

19. Tomfohr LM, Buliga E, Letourneau NL, Campbell TS, Giesbrecht GF. Trajectories of sleep quality and associations with mood during the perinatal period. Sleep 2015; 38: 1237-1245.

20. Mellor R, Chua S, Boyce P. Antenatal depression: an artefact of sleep disturbance? Arch Womens Ment Health 2014; 17:291e302. 
21. Skouteris H, Germano C, Wertheim E, Paxton S, Milgrom J. Sleep quality and depression during pregnancy: a prospective study. J Sleep Res 2008; 17: $217 \mathrm{e} 20$.

22. Okun M, Schetter C, Glynn L. Poor sleep quality is associated with preterm birth. Sleep 2011; 34:1493e8.

23. *August EM, Salihu HM, Biroscak BJ, Rahman S, Bruder K, Whiteman VE. Systematic review on sleep disorders and obstetric outcomes: scope of current knowledge. Am J Perinatol 2012; $30: 323-34$.

24. Naghi I, Keypour F. Sleep disturbance in late pregnancy and type and duration of labour. $J$ Obstet Gynaecol (Lahore) 2011; 31:489e91.

25. Cardwell MS. Stress: pregnancy considerations. Obstet Gynecol Surv 2013; 68:119-29.

26. Spiegel K, Knutson K, Leproult R, Tasali E, Van Cauter E. Sleep loss: a novel risk factor for insulin resistance and Type 2 diabetes. J Appl Physiol 2005; 99:2008-19.

27. Dimidjian S, Goodman S. Nonpharmacologic intervention and prevention strategies for depression during pregnancy and the postpartum. Clin Obstet Gynecol 2009; 52: 498-515.

28. *Mindell JA, Jacobson BJ. Sleep disturbances in pregnancy. JOGNN 2000; 29: 590-597.

29. Becker M, Weinberger T, Chandy A, Schmukler S. Depression during pregnancy and postpartum. Curr Psychiatry Rep 2016; 18: 32.

30. Sherman LJ, Ali MM. Diagnosis of Postpartum Depression and Timing and Types of Treatment Received Differ for Women with Private and Medicaid Coverage. Women's Health Issues 2018; 28: 524-529.

31. Arch JJ. Cognitive behavioral therapy and pharmacotherapy for anxiety: treatment preferences and credibility among pregnant and non-pregnant women. Behav Res Ther 2014; 52:53-60. 
32. O'connor E, Rossom RC, Henninger M, Groom HC, Burda BU. Primary care screening for and treatment of depression in pregnant and postpartum women: evidence report and systematic review for the US Preventive Services Task Force. JAMA 2016; 315: 388-406.

33. O'hara MW, Stuart S, Gorman LL, Wenzel A. Efficacy of interpersonal psychotherapy for postpartum depression. Arch Gen Psychiatry 2000; 57:1039-1045.

34. Baylis F. Pregnant women deserve better. Nature 2010; 465: 689-690.

35. Qaseem A, Kansagara D, Forciea MA, Cooke M, Denberg TD. Management of chronic insomnia disorder in adults: a clinical practice guideline from the American College of Physicians. Ann Intern Med 2016; 165: 125-133.

36. Ballesio A, Aquino MRJV, Feige B, Johann AF, Kyle S D, Spiegelhalder K et al. The effectiveness of behavioural and cognitive behavioural therapies for insomnia on depressive and fatigue symptoms: a systematic review and network meta-analysis. Sleep Med Rev 2018, 37: 114-129.

37. Wu J Q, Appleman E R, Salazar R D, Ong JC. Cognitive behavioral therapy for insomnia comorbid with psychiatric and medical conditions: a meta-analysis. JAMA Intern Med 2015; 175: $1461-1472$.

38. *Johann A, Baglioni C, Hertenstein E, Riemann D, Spiegelhalder K. Prevention of mental disorders through cognitive behavioral therapy for insomnia. Somnologie 2015; 19: 88-92.

39. Sedov ID, Goodman SH, Tomfohr-Madsen LM. Insomnia treatment preferences during pregnancy. J Obstet Gynecol Neonatal Nurs 2017; 46: e95-e104.

40. *Liberati A, Altman DG, Tetzlaff J, Mulrow C, Gøtzsche PC, Ioannidis JP, et al., The PRISMA statement for reporting systematic reviews and meta-analyses of studies that evaluate health care interventions: explanation and elaboration. PLoS medicine 2009; 6: e1000100. 
41. O'Connor D, Green S, Higgins JPT (2008) Chapter 5: Defining the review question and developing criteria for including studies. In: Higgins JPT, Green S, editors. Cochrane handbook for systematic reviews of interventions version 5.0.0 [updated February 2008]. The Cochrane Collaboration. Available: http://www.cochrane-handbook.org/.

42. Higgins JP, Altman DG, Gøtzsche PC, Jüni P, Moher D, Oxman AD, et al., The Cochrane Collaboration's tool for assessing risk of bias in randomised trials. BMJ 2011; 343: d5928.

43. Effati-Daryani F, Mohammad-Alizadeh-Charandabi S, Mirghafourvand M, Taghizadeh M, Bekhradi R, Zarei S. Effect of Lavender cream with or without footbath on sleep quality and fatigue in pregnancy and postpartum: a randomized controlled trial. Women Health 2018; 58: 1179-1191.

44. Khazaie H, Ghadami MR, Knight DC, Emamian F, Tahmasian M. Insomnia treatment in the third trimester of pregnancy reduces postpartum depression symptoms: a randomized clinical trial. Psychiatry Res 2013; 210: 901-905.

45. *Manber R, Bei B, Simpson N, Asarnow L, Rangel E, Sit A, et al. Cognitive Behavioral Therapy for Prenatal Insomnia: A Randomized Controlled Trial. Obstet Gynecol 2019; 133: 911-919.

46. Özkan SA, Rathfisch G The effect of relaxation exercises on sleep quality in pregnant women in the third trimester: A randomized controlled trial. Complement Ther Clin Pract 2018; 32: 7984.

47. Pour ZS, Hosseinkhani A, Asadi N, Shahraki HR, Vafaei H, Kasraeian M, et al. Double-blind randomized placebo-controlled trial on efficacy and safety of Lactuca sativa L. seeds on pregnancy-related insomnia. Journal Ethnopharmacol 2018; 227: 176-180. 
48. Rezaei E, Moghadam ZB, Nejat S, Dehghannayeri N. The impact of sleep healthy behavior education on the quality of life in the pregnant women with sleep disorder: A randomized control trial in the year 2012. Iran J Nurs Midwifery Res 2014; 19: 508.

49. Guerreiro da Silva JB, Nakamura MU, Cordeiro JA, Kulay Jr L. Acupuncture for insomnia in pregnancy-a prospective, quasi-randomised, controlled study. Acupunct Med 2005; 23: 47-51.

50. Beddoe AE, Lee KA, Weiss SJ, Powell Kennedy H, Yang CPP. Effects of mindful yoga on sleep in pregnant women: a pilot study. Biol Res Nurs 2010; 11: 363-370.

51. Liu YH, Lee CS, Yu CH, Chen CH. Effects of music listening on stress, anxiety, and sleep quality for sleep-disturbed pregnant women. Women Health 2016; 56: 296-311.

52. Schaffer L, Jallo N, Howland L, James K, Glaser D, Arnell K. Guided imagery: an innovative approach to improving maternal sleep quality. Journal Perinat Neonatal Nurs 2013; 27: 151159.

53. Lee KA, Gay CL, Alsten CR, Sleep enhancement training for pregnant women. Obstet Gynecol 2016; 128: 964.

54. Tomfohr-Madsen LM, Clayborne ZM, Rouleau CR, Campbell TS. Sleeping for two: an openpilot study of cognitive behavioral therapy for insomnia in pregnancy. Behav Sleep Med 2017; 15: 377-393.

55. Lee KA, Gay CL. Improving sleep for hospitalized antepartum patients: a non-randomized controlled pilot study. J Clin Sleep Med 2017; 13: 1445-1453.

56. Felder JN, Laraia B, Coleman-Phox K, Bush N, Suresh M, Thomas M et al. Poor sleep quality, psychological distress, and the buffering effect of mindfulness training during pregnancy. Behav Sleep Med 2018; 16: 611-624.

57. Field T, Hemandez-Reif M, Hart S, Theakston H, Schanberg S, Kuhn C. Pregnant women benefit from massage therapy. J Psychosom Obstet Gynecol 1999; 20: 31-38. 
58. Field T, Diego M, Delgado J, Medina L. Tai chi/yoga reduces prenatal depression, anxiety and sleep disturbances. Complement Ther Clin Pract 2013; 19: 6-10.

59. Bastien CH, Vallières A, Morin CM Validation of the Insomnia Severity Index as an outcome measure for insomnia research. Sleep Med 2001; 2: 297-307.

60. Feren S, Katyal A, Walsh J K. Efficacy of hypnotic medications and other medications used for insomnia. Sleep Med Clin 2006; 1: 387-397.

61. Okun ML, Ebert R, Saini B. A review of sleep-promoting medications used in pregnancy. Am J Obstet Gynecol 2015; 212: 428-441.

62. Juric S, Newport D J, Ritchie J C, Galanti M, Stowe ZN. Zolpidem (Ambien®) in pregnancy: placental passage and outcome. Arch Women Ment Hlt 2009; 12: 441.

63. Garland EL, Roberts-Lewis A, Tronnier CD, Graves R, Kelley K. Mindfulness-oriented recovery enhancement versus CBT for co-occurring substance dependence, traumatic stress, and psychiatric disorders: proximal outcomes from a pragmatic randomized trial. Behav Res Ther 2016; 77: 7-16.

64. Ong JC, Shapiro SL, Manber R. Combining mindfulness meditation with cognitive-behavior therapy for insomnia: a treatment-development study. Behav Ther 2008; 39: 171-182.

65. Ong JC, Ulmer CS, Manber R. Improving sleep with mindfulness and acceptance: a metacognitive model of insomnia. Behav Res Ther 2012; 50: 651-660.

66. Narendran S, Nagarathna R, Narendran V, Gunasheela S, Nagendra HRR. Efficacy of yoga on pregnancy outcome. J Altern Complement Med 2005; 11: 237-244.

67. Urech C, Fink NS, Hoesli I, Wilhelm FH, Bitzer J, Alder J. Effects of relaxation on psychobiological wellbeing during pregnancy: a randomized controlled trial. Psychoneuroendocrinology 2010; 35:1348-1355.

68. Nickel C, Lahmann C, Muehlbacher M, et al., Pregnant women with bronchial asthma benefit 
from progressive muscle relaxation: a randomized, prospective, controlled trial. Psychother Psychosom 2006; 75:237-243.

69. Chuang LL, Lin LC, Cheng PJ, Chen CH, Wue SC, Chang CL. The effectiveness of a relaxation training program for women with preterm labour on pregnancy outcomes: a controlled clinical trial. Int J Nurs Stud 2012; 49: 257-264.

70. Buysse DJ, Reynolds III CF, Monk TH, Berman SR, Kupfer DJ The Pittsburgh Sleep Quality Index: a new instrument for psychiatric practice and research. Psychiatry Res 1989; 28: 193213.

71. Theorell-Haglow J, Lindberg E, Janson C. What are the important risk factors for daytime sleepiness and fatigue in women? Sleep 2006; 29:751-757.

72. Foley D, Ancoli-Israel S, Britz P, et al. Sleep disturbances and chronic disease in older adults: Results of the 2003 National Sleep Foundation Sleep in America Survey. J Psychosom Res 2004; 56:497-502.

73. Vgontzas AN, Bixler EO, Tan TL, et al. Obesity without sleep apnea is associated with daytime sleepiness. Arch Intern Med 1998; 158:1333-1337.

74. CRD, University of York; 2009. Jan, Systematic Reviews: CRD's guidance for undertaking reviews in health care. Centre for Reviews and Dissemination, University of York, 2008 
Table 1: Study characteristics

\begin{tabular}{|c|c|c|c|c|c|c|c|c|c|}
\hline Study & $\begin{array}{c}\text { Population } \\
\text { characteristics }\end{array}$ & $\begin{array}{c}\text { Sample } \\
\text { size }\end{array}$ & $\begin{array}{l}\text { Mean age } \\
\text { (years) }\end{array}$ & $\begin{array}{c}\text { Mean } \\
\text { Gestational } \\
\text { Age } \\
\text { (weeks) }\end{array}$ & Study design & Country & Interventions & $\begin{array}{l}\text { Duration of } \\
\text { the } \\
\text { intervention }\end{array}$ & Sleep outcome \\
\hline $\begin{array}{l}\text { Beddoe AE } \\
\text { et al., } 2010 \\
\text { [50] }\end{array}$ & Healthy & 15 & 30.2 & 23.3 & Intervention study & USA & $\begin{array}{c}\text { Mindfulness } \\
\text { based yoga vs } \\
\text { baseline data }\end{array}$ & $7 \mathrm{wk}$ & $\begin{array}{l}\text { Self-reported } \\
\text { sleep disturbance } \\
\text { and sleep } \\
\text { parameter by } \\
\text { actigraph }\end{array}$ \\
\hline $\begin{array}{c}\text { Felder JN } \\
\text { et al., } 2018 \\
{[56]}\end{array}$ & $\begin{array}{c}\text { Obese / } \\
\text { Overweight } \\
\text { women }\end{array}$ & 215 & 27.8 & 17.4 & Intervention study & USA & $\begin{array}{c}\text { Mindful moms } \\
\text { training (MMT) } \\
\text { vs treatment as } \\
\text { usual }\end{array}$ & 8 wk & $\begin{array}{l}\text { Self-reported } \\
\text { sleep quality }\end{array}$ \\
\hline $\begin{array}{c}\text { Field T et } \\
\text { al., } 1999 \\
{[57]}\end{array}$ & Healthy & 26 & 29 & 23.5 & Intervention study & USA & $\begin{array}{l}\text { Massage therapy } \\
\text { vs control } \\
\text { relaxation therapy }\end{array}$ & $5 \mathrm{wk}$ & $\begin{array}{c}\text { Self-reported } \\
\text { sleep disturbance }\end{array}$ \\
\hline $\begin{array}{l}\text { Field T et } \\
\text { al., } 2013 \\
\quad[58]\end{array}$ & $\begin{array}{l}\text { Women with } \\
\text { clinical } \\
\text { depression }\end{array}$ & 92 & 26.6 & 22 & Intervention study & USA & $\begin{array}{l}\text { Yoga \& tai chi vs } \\
\text { waiting list }\end{array}$ & $12 \mathrm{wk}$ & $\begin{array}{c}\text { Self-reported } \\
\text { sleep disturbance }\end{array}$ \\
\hline $\begin{array}{c}\text { Guerreiro } \\
\text { da Silva JB } \\
\text { et al., } 2005 \\
{[49]}\end{array}$ & $\begin{array}{l}\text { Healthy, with } \\
\text { reported sleep } \\
\text { problems }\end{array}$ & 30 & 26.5 & 21.4 & $\begin{array}{l}\text { Prospective, quasi- } \\
\text { randomized, } \\
\text { controlled study }\end{array}$ & Brazil & $\begin{array}{l}\text { Acupuncture vs } \\
\text { sleep hygiene }\end{array}$ & $8 \mathrm{wk}$ & $\begin{array}{l}\text { Self-reported } \\
\text { sleep disturbance }\end{array}$ \\
\hline
\end{tabular}




\begin{tabular}{|c|c|c|c|c|c|c|c|c|c|}
\hline $\begin{array}{c}\text { Lee } K A \text { et } \\
\text { al., 2016 } \\
\text { [53] }\end{array}$ & Healthy & 25 & 32.7 & 29 & Intervention study & USA & $\begin{array}{l}\text { Home-based sleep } \\
\text { enhancement } \\
\text { training system } \\
\text { for pregnancy vs } \\
\text { control groups of } \\
\text { another study }\end{array}$ & $4 \mathrm{wk}$ & $\begin{array}{l}\text { Sleep parameter } \\
\text { by actigraph }\end{array}$ \\
\hline $\begin{array}{l}\text { Lee KA \& } \\
\text { Gay CL, } \\
2017[55]\end{array}$ & Healthy & 25 & 32.9 & 29 & $\begin{array}{l}\text { Non-Randomized } \\
\text { Controlled Pilot } \\
\text { Study }\end{array}$ & USA & $\begin{array}{c}\text { Sleep } \\
\text { improvement } \\
\text { protocol from } \\
\text { antepartum } \\
\text { patients (SIP-AP) } \\
\text { vs usual prenatal } \\
\text { care }\end{array}$ & $7 d$ & $\begin{array}{l}\text { Self-reported } \\
\text { sleep disturbance, } \\
\text { sleep quality and } \\
\text { sleep duration, } \\
\text { sleep parameter } \\
\text { by sleep diaries }\end{array}$ \\
\hline $\begin{array}{l}\text { Liu YH et } \\
\text { al., 2016 } \\
\text { [51] }\end{array}$ & $\begin{array}{l}\text { Healthy, with } \\
\text { reported sleep } \\
\text { problems }\end{array}$ & 121 & $\begin{array}{l}\text { Not } \\
\text { reported }\end{array}$ & Not reported & $\begin{array}{l}\text { Not randomized } \\
\text { controlled trial }\end{array}$ & Taiwan & $\begin{array}{l}\text { Music therapy } \\
\text { (Listening CD) vs } \\
\text { usual prenatal } \\
\text { care }\end{array}$ & $2 \mathrm{wk}$ & $\begin{array}{l}\text { Self-reported } \\
\text { sleep quality }\end{array}$ \\
\hline $\begin{array}{c}\text { Khazaie } H \\
\text { et al., } 2013 \\
\text { [44] }\end{array}$ & $\begin{array}{l}\text { Healthy, with } \\
\text { reported sleep } \\
\text { problems }\end{array}$ & 54 & 26.5 & 28 & $\begin{array}{l}\text { Randomized } \\
\text { controlled trial }\end{array}$ & Iran & $\begin{array}{l}\text { Trazodone;Diphe } \\
\text { nhydramine vs } \\
\text { Placebo }\end{array}$ & $6 \mathrm{wk}$ & $\begin{array}{l}\text { Sleep parameter } \\
\text { by actigraph }\end{array}$ \\
\hline $\begin{array}{c}\text { Manber } R \\
\text { et al., } 2019 \\
\text { [45] }\end{array}$ & Insomniac & 179 & 33 & 24.7 & $\begin{array}{l}\text { Randomized } \\
\text { controlled trial }\end{array}$ & USA & $\begin{array}{c}\text { Cognitive } \\
\text { behavioral } \\
\text { therapy for } \\
\text { insomnia (CBT-I) } \\
\text { vs control therapy }\end{array}$ & $5 \mathrm{wk}$ & $\begin{array}{l}\text { Self reported } \\
\text { severity of } \\
\text { insomnia; sleep } \\
\text { parameter by } \\
\text { sleep diaries and } \\
\text { actigraph }\end{array}$ \\
\hline $\begin{array}{c}\ddot{O} \text { zkan } S A \\
\& \\
\text { Rathfisch } \\
\text { G, 2018 } \\
{[46]}\end{array}$ & Healthy & 84 & 27.8 & Not reported & $\begin{array}{l}\text { Randomized } \\
\text { controlled trial }\end{array}$ & Turkey & $\begin{array}{l}\text { Relaxation vs } \\
\text { standard care }\end{array}$ & $4 \mathrm{wk}$ & $\begin{array}{c}\text { Self-reported } \\
\text { sleep quality, } \\
\text { sleep duration and } \\
\text { sleep disturbances }\end{array}$ \\
\hline
\end{tabular}




\begin{tabular}{|c|c|c|c|c|c|c|c|c|c|}
\hline $\begin{array}{c}\text { Pour ZS et } \\
\text { al., 2018 } \\
\text { [47] }\end{array}$ & $\begin{array}{l}\text { Healthy, with } \\
\text { reported sleep } \\
\text { problems }\end{array}$ & 100 & 29.4 & 30.6 & $\begin{array}{l}\text { Randomized } \\
\text { controlled trial }\end{array}$ & Iran & $\begin{array}{l}\text { Lactuca sativa } L \text {. } \\
\text { seeds vs placebo }\end{array}$ & $2 \mathrm{wk}$ & $\begin{array}{l}\text { Self reported } \\
\text { sleep quality }\end{array}$ \\
\hline $\begin{array}{c}\text { Rezaei E et } \\
\text { al., } 2014 \\
{[48]}\end{array}$ & $\begin{array}{l}\text { Healthy, with } \\
\text { reported sleep } \\
\text { problems }\end{array}$ & 112 & 26.8 & 17.8 & $\begin{array}{l}\text { Randomized } \\
\text { controlled trial }\end{array}$ & Iran & $\begin{array}{c}\text { Education of sleep } \\
\text { health behavior vs } \\
\text { usual prenatal } \\
\text { care }\end{array}$ & $4 \mathrm{wk}$ & $\begin{array}{l}\text { Self reported } \\
\text { sleep quality }\end{array}$ \\
\hline $\begin{array}{c}\text { Schaffer } L \\
\text { et al., } 2013 \\
\text { [52] }\end{array}$ & Healthy & 20 & 27.3 & 28 & Intervention study & USA & $\begin{array}{l}\text { Relaxation guided } \\
\text { imagery }\end{array}$ & $8 \mathrm{wk}$ & $\begin{array}{l}\text { Self reported } \\
\text { sleep quality }\end{array}$ \\
\hline $\begin{array}{l}\text { Tomfohr- } \\
\text { Madsen } \\
\text { LM et al., } \\
2017 \text { [54] }\end{array}$ & $\begin{array}{l}\text { Healthy, with } \\
\text { reported sleep } \\
\text { problems }\end{array}$ & 13 & 31 & 19.3 & Intervention study & Canada & $\begin{array}{c}\text { Cognitive } \\
\text { behavioral } \\
\text { therapy for } \\
\text { insomnia }(\mathrm{CBT}-\mathrm{I})\end{array}$ & $5 \mathrm{wk}$ & $\begin{array}{l}\text { Self reported } \\
\text { severity of } \\
\text { insomnia; sleep } \\
\text { parameter by } \\
\text { sleep diaries and } \\
\text { actigraph }\end{array}$ \\
\hline
\end{tabular}


Table 2: Efficacy of different intervention on assessed outcome

\begin{tabular}{|c|c|c|c|c|c|c|c|}
\hline Intervention & $\begin{array}{c}\text { Randomzied } \\
\text { Controlled } \\
\text { Trial } \\
(\text { Yes } / \text { No })\end{array}$ & $\begin{array}{l}\text { Number of } \\
\text { session } \\
(\mathbf{n}=)\end{array}$ & $\begin{array}{l}\text { Follow up } \\
(\text { Yes/No) }\end{array}$ & $\begin{array}{l}\text { Sleep } \\
\text { quality }\end{array}$ & $\begin{array}{l}\text { Self reported } \\
\text { sleep } \\
\text { disturbance }\end{array}$ & $\begin{array}{c}\text { Sleep } \\
\text { parameters by } \\
\text { actigraph }\end{array}$ & $\begin{array}{c}\text { Sleep } \\
\text { parameters } \\
\text { by sleep } \\
\text { diaries }\end{array}$ \\
\hline \multicolumn{8}{|l|}{$\begin{array}{l}\text { Cognitive Behavioral } \\
\text { Therapy interventions }\end{array}$} \\
\hline Manber R et al., 2019 [45] & Yes & 5 weeks & No & & $\checkmark$ & $x$ & $\checkmark$ \\
\hline $\begin{array}{l}\text { Tomfohr-Madsen LM et al., } \\
2017 \text { [54] }\end{array}$ & No & 5 weeks & No & $\checkmark$ & $\checkmark$ & $\checkmark$ & $\checkmark$ \\
\hline Lee KA \& Gay CL, 2017 [55] & No & 7 days & No & $x$ & $\checkmark$ & & $x$ \\
\hline Rezaei E et al., 2014 [48] & Yes & 4 weeks & $\begin{array}{l}\text { Yes ( } 1 \text { and } 2 \\
\text { months after } \\
\text { the } \\
\text { intervention })\end{array}$ & $\checkmark$ & & & \\
\hline
\end{tabular}

Pharmacotherapy 


$\begin{array}{cccc} & & \text { Yes }(2 \text { and } 6 & \checkmark \text { only at } \\ \text { Khazaie H et al., 2013 [44] } & \text { Yes } & 6 \text { weeks } & \text { weeks after } \\ \text { intervention) } & \text { follow up }\end{array}$

Mindfulness

\begin{tabular}{lcccc}
\hline Beddoe AE et al., 2010 [50] & No & 7 weeks & No & $\checkmark$ \\
Felder JN et al., $2018[56]$ & No & 8 weeks & No & \\
Field T et al., $2013[58]$ & No & 12 weeks & No & \\
\hline
\end{tabular}

Relaxation

\begin{tabular}{|c|c|c|c|c|c|}
\hline Liu YH et al., 2016 [51] & No & 2 weeks & No & $\checkmark$ & \\
\hline Schaffer L et al., 2013 [52] & No & 8 weeks & No & $\checkmark$ & \\
\hline Field T et al., 1999 [47] & No & 5 weeks & No & & $\checkmark$ \\
\hline $\begin{array}{c}\text { Özkan SA \& Rathfisch } G \text {, } \\
2018[46]\end{array}$ & Yes & 4 weeks & No & $\checkmark$ & $\checkmark$ \\
\hline
\end{tabular}


Alternative

\begin{tabular}{ccccc}
\hline $\begin{array}{c}\text { Guerreiro da Silva JB et al., } \\
\text { 2005 [49] }\end{array}$ & No & 8 weeks & No & $\checkmark$ \\
$\begin{array}{c}\text { Effati-Daryani F et al., 2018 } \\
\text { [43] }\end{array}$ & Yes & $\begin{array}{c}\text { During } \\
\text { pregnancy and } \\
\text { after delivery }\end{array}$ & $\begin{array}{c}\text { 6 weeks after } \\
\text { delivery }\end{array}$ & $\checkmark$ \\
Pour ZS et al., 2018 [47] & Yes & 2 weeks & No & $\checkmark$
\end{tabular}

(Legend: $\checkmark=$ the intervention was efficacy in this outcome; $X=$ the intervention was not efficacy in this outcome) 
Figure 1: Search flow diagram

\section{PRISMA 2009 Flow Diagram}

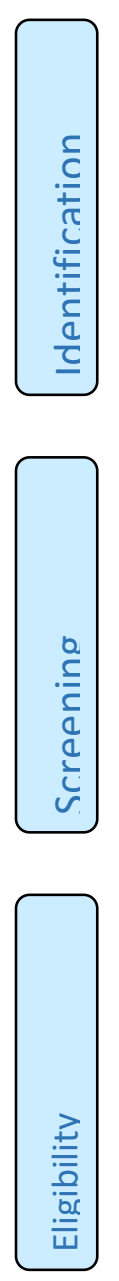

Records identified through

database searching

( $\mathrm{n}=1748$ Pubmed

$\mathrm{n}=1038$ Medline

$\mathrm{n}=439$ Psychinfo) sources (contact with experts, search for abstracts in conference proceedings; ) ( $\mathrm{n}=0$ abstracts in conference proceedings
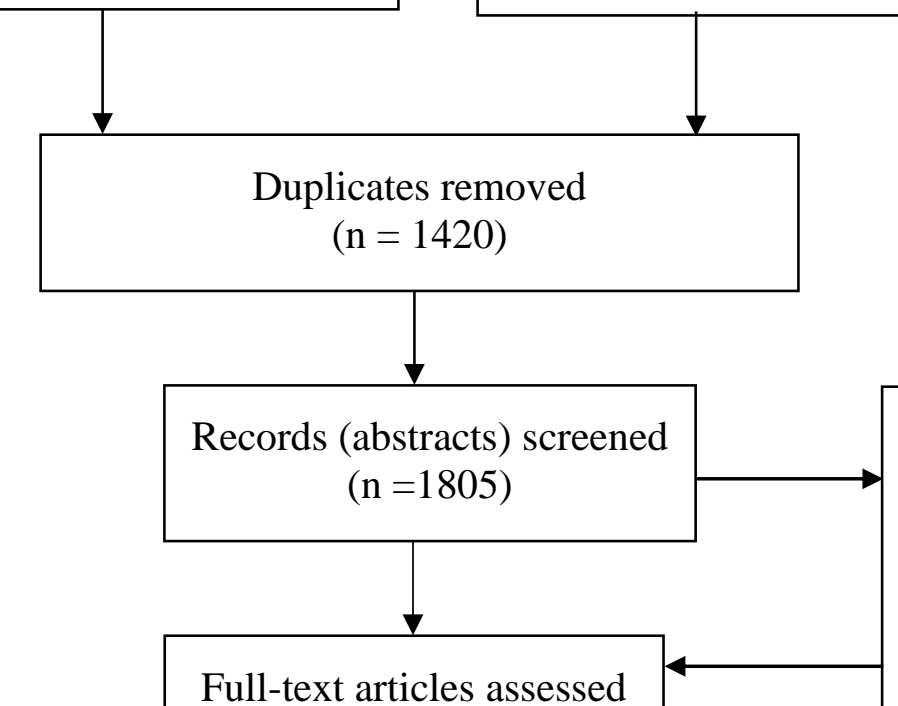

Records (abstracts) excluded

$(\mathrm{n}=1785)$

Reasons:

Population: pregnant women

Study design: clinical intervention targeting sleep quality, insomnia or insomnia related for eligibility

$(\mathrm{n}=20)$ symptoms

Comparator group and Outcomes: pre and post treatment data for both intervention and controls (when available)

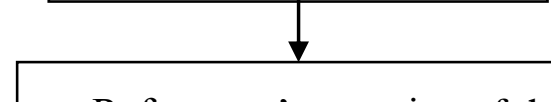

References' screening of the screened full-texts. $(\mathrm{n}=0)$

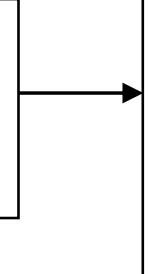

Full-text articles excluded, with reasons

$\mathrm{n}=2$ (Study design) $\mathrm{n}=2$ (Not insomnia or sleep as primary or secondary outcome)

Studies included in qualitative synthesis 